\title{
Dependence of Losses from Natural Hazards on the Prosperity of Societies: A Brief Review
}

\author{
MV Rodkin* \\ Institute of Earthquake Prediction Theory and Mathematical Geophysics, Russian Academy of Sciences, Moscow, Russia \\ *Corresponding author: MV Rodkin, Institute of Earthquake Prediction Theory and Mathematical Geophysics, Russian Academy of \\ Sciences, Moscow, Russia
}

\begin{abstract}
The losses due to natural disasters depend, not only on the magnitude of natural destructive factors, but also on the socioeconomic situation in the society and its capability to withstand those natural factors. Overall, as the Technosphere is developing and the national wealth increases, the economic losses from disasters become larger, while the number of casualties stabilizes, or even decreases. This tendency is especially pronounced when countries with different levels of economic maturity are compared. Viewing the historical past, we can see not infrequent cases in which major natural disasters preceded the conquest of the political community concerned. However, the converse can also happen: A developing socio-economic crisis results in greater vulnerability and favors especially large losses.
\end{abstract}

\section{Short Communication}

The discussion of losses due to natural hazards and maninduced catastrophes would be reasonable to begin by a very brief review of the main tendencies observable in the time-dependent variation in the rate of disasters and the associated losses (more detailed accounts can be found in the two monographs by $[1,2])$. We begin by a brief discussion of the basic stationary regime of losses. Now at the outset we are forced to ask ourselves whether we can treat the loss caused by disasters as a function of time as a stationary one, even in a rough approximation. The statistical data provide reliable evidence of an increasing rate of natural disasters and of the associated losses over time. This tendency is frequently viewed as resulting from increasing population, urbanization, a growing number of hazardous facilities, and a general deterioration of the geo ecologic environment $[3,4]$. This interpretation is not however entirely correct. The increasing rate of disasters may be due to an increasing awareness of comparatively insignificant disasters that have occurred in remote regions and which have gone unnoticed before. It is easy to see that the tendency of increase in the rate of disasters is related to the increasing rate of just smaller events. A possible stationary interpretation can also be applied to the tendency of a nonlinear growth of total loss due to natural disasters over time. This can be seen as follows. The distribution of losses (both economic loss and the number of casualties) due to natural disasters (hurricanes, earthquakes, others) is commonly described by a power law whose mean is theoretically speaking infinite. Now as long as this kind of a distribution law holds, the sampling mean of the losses as a function of time will tend to its limiting value (which is theoretically speaking infinite), hence it will increase. Naturally enough, this tendency due to the power law distribution of losses cannot last indefinitely long. Evidently, any actual values of the number of casualties and economic losses are finite. Accordingly, eventually the maximum loss will increase at a decelerating rate and ultimately cease growing, while the growth of total loss would become stationary and linear over time. The time span when this change in the growth of loss values with time would occur is different for different regions and for different kinds of disaster, usually being a few decades $[1,5]$.

We wish to emphasize the circumstance that the above temporary nonlinear growth of disaster losses over time as discussed above will be observed in the strictly stationary case. But this growth will take place only over limited time spans, when the finiteness of maximum losses cannot be observed yet statistically, and while the power-law distribution of loss values is yet valid. It is also obvious that, apart from this mechanism of the nonlinear growth of losses over time, another mechanism can operate related to actual non stationarities in both natural conditions and the characteristics of the human community (population size, techno sphere development, other factors). The real non stationarity of natural disasters can be caused, e.g., by the climate change. 
Now we turn to a discussion of how the losses from natural disasters change in relation to the technological development of mankind and growing population. Overall, it turns out that the magnitude of economic loss due to disasters increases with increasing national wealth of the respective countries and regions. However, the rate of casualties due to natural disasters tends to decrease as the techno sphere is developing, in spite of the growing population. This tendency is especially pronounced in developed countries.

Taking the case of earthquakes, one example showing the ratio between economic loss to casualties as a function of GDP per capita is displayed in Figure 1. One clearly sees a relationship between these variables, so that the normalized loss is factually a function of economic development.

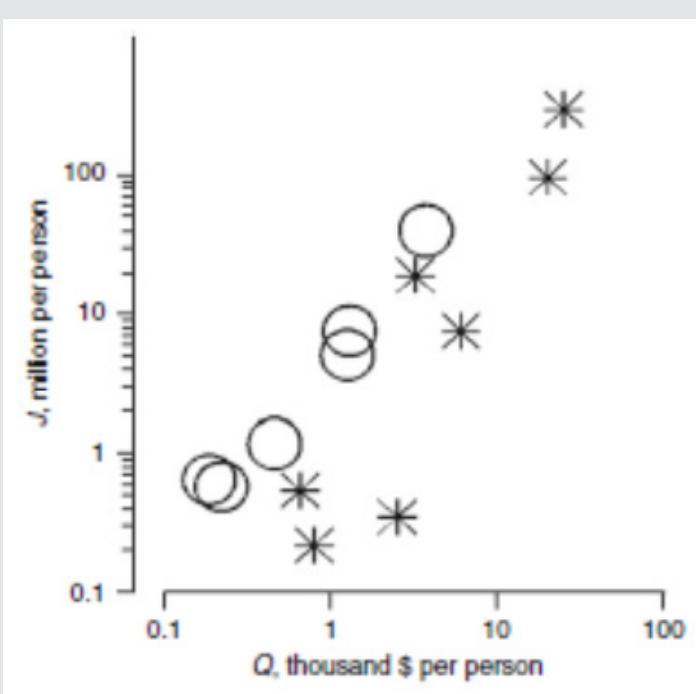

Figure 1: Change of "loss/casualties" ratio J with the annual per capita national product Q based on the mean data for different regions (circles) and for the individual earthquakes hitting large cities (asterisks), based on data from [1].

However, the losses due to natural disasters are also affected by shorter term economic and political factors. Figures $2 \& 3$ show the time series of the norm number of casualties in China and that of the number of significant (reliably recorded) natural disasters in Russia during the $20^{\text {th }}$ century. Both of these cases clearly demonstrate non stationarity in the losses due to disasters, with the maxima of sensitivity of a community to natural disasters that occur during war time, during the Chinese cultural revolution, the 1990s crisis in Russia, and even in response to such a short-lived event as the 1998 default in Russia.

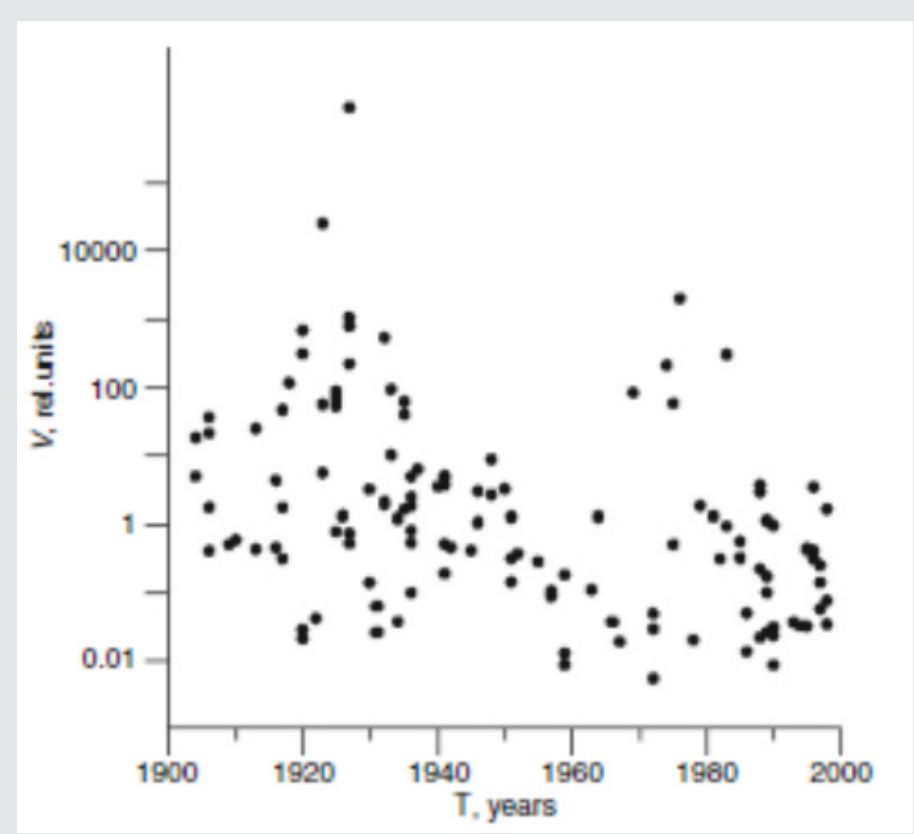

Figure 2: The death toll V (in arbitrary units) normalized on the population of China and earthquake energy. The relative growth of vulnerability of society during the Civil War and intervention, and in the later years of the Cultural Revolution along with a marked decrease in normalized death tolls toward the end of the twentieth century, after [1]. 


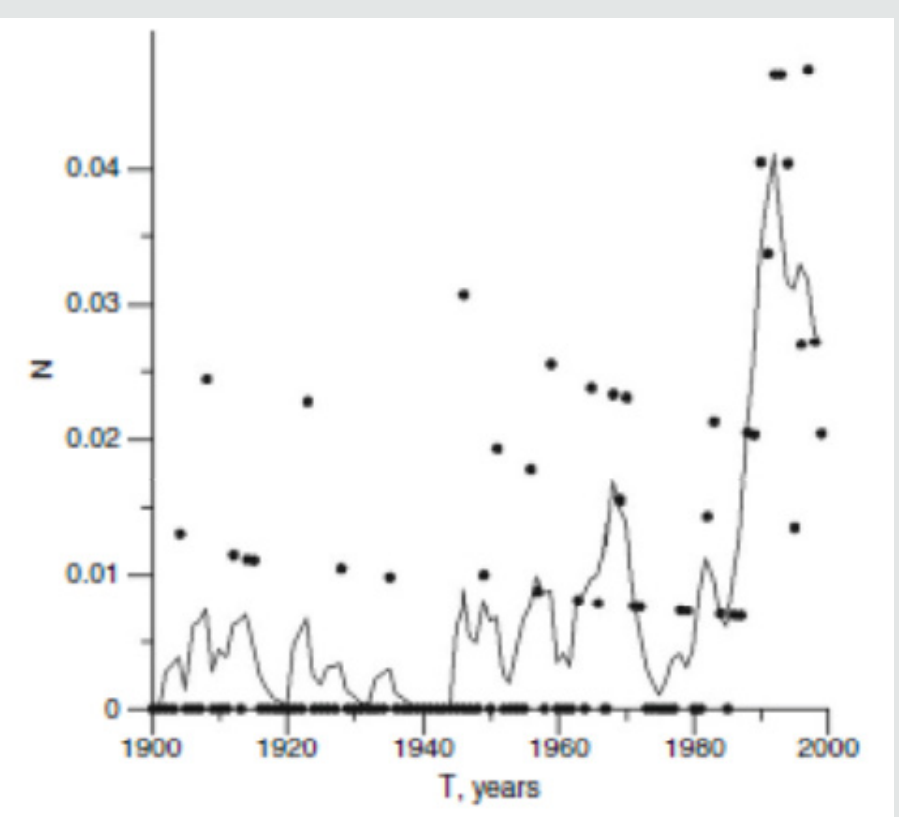

Figure 3: Annual number of major disasters in Russia per million population (dots) and averaged values on overlapping 5-year intervals (line), after [1].

The relationship between the impact of natural disasters and the history of different societies can be seen also in historical and archeo seismological evidence. For example, in Gladkov [6]; Korzhenkov [7] and Korzhenkov [8]; Rodkin \& Korzhenkov [9] quote data on major earthquake-induced damages to pre-Mongolian settlements around Lake Issyk Kul and to ancient (before the Arab conquest) agrarian settlements in Negev Desert, Israel, respectively. In both of these cases, major earthquake-induced devastations preceded the conquest of these regions. In result the well-developed before irrigation systems were not restored, and the land use changes to a more backward nomadic cattle-breeding type of land use.

The above discussion provides examples of how natural disasters and the consequent losses are related to the stability and successfulness of human communities. It is quite to be expected that major natural disasters could significantly sap the socio-economic potential of the society, thereby making it more vulnerable to enemy assaults. The effect could be especially pronounced in arid irrigated areas where destruction of cities and ground surface deformations could essentially harm the irrigation systems and cause a mass starvation. However, the opposite relationship could also take place, with a social crisis and associated difficulties in control and emergency measures facilitating especially large losses from natural disasters (likely examples of such a relationship are shown in Figures 2\&3).

In this connection, one might also mention traditions in ancient China, when especially great losses due to natural disasters could be viewed as an additional evidence that the current dynasty has lost the Mandate of Heaven to rule China. It is thought that there were examples in which in the cases of a change of a dynasty data on losses occurring from previous disasters were modified (increased) in order to produce evidence that the ousted dynasty has lost its Mandate of Heaven to control China and had to be overthrown [10].
Speaking of more recent times, we can recall a similar tendency of authoritarian regimes making a secret of the magnitude of losses due to natural or man-induced disasters, as happened, e.g., in the former Soviet Union.

Summing up, we can say that natural disasters and the associated losses (more specifically, the excess of their typical values) can be regarded as factors essentially affecting socio-political stability of societies, as well as a possible indirect evidence for incipient socioeconomic crises in a community.

\section{References}

1. Pisarenko VF, Rodkin MV (2010) Heavy-tailed distributions in disaster analysis. Springer, Germany.

2. Pisarenko V, Rodkin M (2014) Statistical Analysis of Natural Disasters and Related Losses. Springer Briefs in Earth Sciences. Springer, Germany, p. 82.

3. Berz G (1992) Munich Re's list of major disasters in 1990. Natural Hazards 5: 95-102.

4. Osipov VI (2002) Natural hazard control. Vestnik RAN 8: 678-686.

5. Pisarenko V, Rodkin M (2019) A Collection of Statistical Methods for Analysis of the Disaster Damages and the Seismic Regime. Geographies of the Anthropocene 2(2): 43-63.

6. Gladkov AS, EU Lobova, EV Deev, AM Korzhenkov, JV Mazeika, et al. (2016) Earthquake-induced soft-sediment deformation structures in Late Pleistocene lacustrine deposits of Issyk-Kul Lake (Kyrgyzstan). Sedimentary Geology 344: 112-122.

7. Korzhenkov AM, JR Arrowsmith, CJ Crosby, B Guralnik, EA Rogozhin, et al. (2018) Strong Paleoearthquakes along the Aksuu Border Fault according to the Results of Dating the Offset Terrace Complex of the Chon-Aksuu River, Northern Tien Shan. Izvestiya, Physics of the Solid Earth 54(2): 252-268.

8. Korzhenkov A, Mazor E (2014) Archaeoseismological Damage Pattern at the Ancient Ruins of Rehovot-ba-Negev, Israel. Archaeologischer Anzeiger 1: 75-92. 
9. Rodkin MV, AM Korzhenkov (2019) Estimation of maximum mass velocity from macroseismic data: A new method and application to archeoseismological data. Geodesy and Geodynamics10: 321-330.
10. Yang CK (1961) Operation on the Mandate of Heaven. Yang C.K. Religion in Chinese Society. Los Angeles, USA.
(C) This work is licensed under Creative

To Submit Your Article Click Here: Submit Article

DOI: $10.32474 / J A A S .2020 .01 .000123$

\begin{tabular}{l} 
Journal Of Anthropological And \\
Archaeological Sciences \\
Assets of Publishing with us \\
- Global archiving of articles \\
\hline - Immediate, unrestricted online access \\
\hline Aoumal of Anthropological and
\end{tabular}

